TEMPUS. Revista en Historia General

Medellín (Colombia), 2018, septiembre-octubre, número 8

ISSN: 2422-2976

\title{
LAS MASAS Y EL TIEMPO: LA MANIPULACIÓN DEL TIEMPO EN LOS HECHOS HITO-HISTÓRICOS COMO FORMA DE PODER EN ELIAS CANETTI
}

\author{
CROWDS AND TIME. TIME'S MANIPULATION IN THE MILESTONE- \\ HISTORICAL FACTS AS FORM OF POWER IN ELIAS CANETTI
}

Francisco Miguel Ortiz Delgado ${ }^{1}$ Universidad Autónoma Metropolitana-I. México

DOI: 10.17533/udea.tempus.n8a05

\section{Resumen}

En el presente artículo se reflexiona críticamente en torno a una posible utilización del tiempo como herramienta de poder por los gobernantes políticos de diferentes sociedades del mundo, en especial en los hechos estimados como hito-históricos, según la obra Masa y poder de Elias Canetti. A lo largo del texto analizo que para Canneti: (a) Es un hecho evidente el uso de la temporalidad como un instrumento para controlar o manipular a las masas y a las sociedades; (b) El uso del tiempo por parte de los detentadores del poder fue y es diferente en las diversas épocas del mundo; (c) La idea del tiempo como poder fue sentido de diferentes formas por las diversas masas y pueblos del mundo. En una segunda parte del artículo argumento que en la obra de Canetti se encuentran generalizaciones fuera de lugar o aserciones no comprobables históricamente hablando.

Palabras Clave: Masas, Tiempo, Historia del poder, Teoría política, Poder simbólico.

\begin{abstract}
In the present article it is reflected critically about a possible time's use as a power's instrument by the political leaders in different societies around the world, specially in the actions considered as milestone-historical, according to Elias Canetti's Crowd and

\footnotetext{
${ }^{1}$ Doctorando en Humanidades por la Universidad Autónoma Metropolitana-Iztapalapa. Maestro en filosofía por la UNAM. Licenciado en historia. Miembro del Seminario de Retórica y Argumentación de la UAM-I. Autor de investigaciones y publicaciones académicas en las áreas de filosofía de la historia, así como de ética, e historia e historiografía sobre la guerra antigua y moderna.
} 
Power. In this text I expose that for Canetti: (a) It is an evident fact the use of time as an instrument to control and to manipulate crowds and societies; (b) The use of time by the holders of power was and is different in the diverse world epochs; (c) The idea of time as power impacted in different ways by the diverse people or crowds in the world. In the second part of the article I argument that in the work of Canetti are found generalizations out of place or weak and not verifiable assertions historically speaking.

Keywords: Crowds, Time, History of power, Political Theory, Symbolic power.

En el presente texto tenemos el objetivo de corroborar como certeras las siguientes tres ideas que Elias Canetti desarrolla en su texto Masa y poder: (a) Es un hecho recurrente y evidente en la historia el uso del tiempo como un instrumento para controlar o manipular a las masas y a las sociedades; (b) El uso del tiempo por parte de los detentadores del poder fue y es diferente en las diversas épocas del mundo; (c) El uso de la idea del tiempo como poder fue sentido de diferente forma por las diversas masas y pueblos del mundo. Asimismo, en la segunda sección tenemos el propósito de contradecir, mediante ejemplos de la historia y basándonos en reflexiones de intelectuales como Friedrich Nietzsche, algunos otros de los presupuestos y propuestas de Elias Canetti.

\section{El que ejerce el poder puede hacer uso del tiempo para dominar.}

Al poder lo podemos establecer como el "medio de comunicación, $[\ldots]$ un código de símbolos generalizados que posibilita la transmisión de decisiones, es decir, que transmite la posibilidad de reducir la complejidad para el otro". ${ }^{2}$ Sin identificar poder con política, pues hay más códigos que transmiten decisiones sin que estas provengan de lo político, como es el caso del poder religioso o del económico, y sin considerar al poder como privativamente coercitivo, puesto que hay maneras de ejercer el poder sin emplear la fuerza como en el caso de lo simbólico, es posible así para Canetti demostrar que el tiempo es una herramienta o una forma de poder. Al tener la posibilidad de considerar a la idea de tiempo como un conjunto de símbolos manipulable y al

\footnotetext{
${ }^{2}$ Nora Rabotnikoff. En busca de un lugar común (México: Universidad Nacional Autónoma de México/Instituto de Investigaciones Filosóficas, 2005), 271.
} 
TEMPUS. Revista en Historia General Medellín (Colombia), 2018, septiembre-octubre, número 8

ISSN: 2422-2976

no otorgarle una cualidad coercitiva intrínseca, el tiempo mismo se convierte en una herramienta versátil de los encumbrados.

Canetti nos provee de múltiples ejemplos del empleo del tiempo como poder simbólico y/o coercitivo ${ }^{3}$ (tengamos en claro desde ya que nuestro autor fue criticado por el mismo Theodor Adorno por haber "retornado" a un pensamiento en el que no se distingue entre "imagen y realidad", distinguiremos un tiempo "real" de uno "simbólico" o "abstracto") en los hechos que podemos llamar hito-históricos, es decir, en los hechos que serán interpretados por un grupo de personas (no siempre la cúpula gobernante) como los más sobresalientes e importantes del pasado de la sociedad o nación en que ocurrieron. Asimismo el búlgaro critica ese tipo de poder simbólico-coercitivo, como a cualquier otro tipo de poder, porque, según varios estudiosos subrayan, en su texto Masa y poder propone novedosamente que las masas no necesitan de un líder. "Tal vez la más radical de éstas [novedades teóricas] es la revelación de que las masas no tienen que ser dirigidas". 5 No es menester pues, para la existencia de la masa, tener un gobernante que la manipule con, entre otras muchas cosas, el uso, disposición y tergiversación del tiempo.

"Podría decir que el valor, la importancia de las masas reales es incomparablemente más grande [más grande que el ámbito de lo simbólico] [...] las dictaduras que hemos visto consisten enteramente en masas, y sin el crecimiento de las masas -y esto es especialmente importante-, sin la consciencia y la simulación artificial de más y más grandes masas, el poder de las dictaduras hubiera sido bastante inconcebible". ${ }^{6}$

Canneti escribió Masa y Poder para averiguar los orígenes y causas del éxito del Tercer Reich en Alemania, y en ese famoso régimen, para nuestro autor, las masas tampoco "necesitaban" del Führer sino que éste sólo catalizó sus pulsiones y necesidades (psicológicas) y de esta forma (entre otras) pudo manipularlas. "Mientras cumplió

\footnotetext{
${ }^{3}$ Elias Canetti. Masa y poder (Madrid: Machark Editores/Alianza Editorial, 1981).

${ }^{4}$ Youssef Ishaghpour, "Metamorfosis e identidad en Elías Canetti", en Daimon Revista de Filosofia, N 38 (2006): 33-48.

${ }^{5}$ Alexander James Ellsworth Laing, "Blinded by His Own "Imagination": The Flaw in Cannetti's Crowd Theory", Social and Political Review, Vol XXII (2011): 18.

${ }^{6}$ Elias Canetti, "Crowds and Power. Conversation with Elias Cannetti". Can one live after Auschwitz? A philosophical reader (California: Stanford University Press, 2003), 188.
} 
sus labores como Führer, no actuó en lo absoluto como la ensalzada contrafigura de una masa guiada por él mismo sino como su delegado y catalizador". ${ }^{7}$ Por lo que Canetti, como diría Karl Popper, no fue uno de esos investigadores (historicistas) que cree "que los actores realmente importantes en el Escenario de la Historia son, o bien las Grandes Naciones y su [sic] Grandes Líderes, o bien, quizá, las Grandes Clases o las Grandes Ideas", 8 sino que, por el contrario, se trata de un intelectual que, para comprender al Nacional-Socialismo, no se enfoca más de lo necesario en Adolf Hitler sino que se centra mucho más en el análisis de las masas que siguieron al Führer como hipnotizados.

Vayamos con un primer ejemplo canettiano del tiempo como forma de poder, el caso de la "rapidez". El realizar las acciones en una duración de tiempo menor que los demás, de manera metafórica o real, fue uno de los mayores símbolos de poder en muchas y muy variadas culturas, nos dice el intelectual. Con lo anterior podemos entender por cuál motivo muchos soberanos y dinastías adoptaron animales u objetos veloces como una representación de ellos. Y Canneti ${ }^{9}$ nos da varios ejemplos históricos: en los egipcios el halcón Horus era el dios personal de los faraones; entre los reinos africanos los animales representantes de la realeza fueron los veloces león y leopardo; el Imperio Romano tuvo al águila como su efigie y fue en especial la del emperador; los mongoles veneraban, respetaban y temían especialmente al rayo; el rayo mismo era el símbolo y atributo exclusivo de los dioses Zeus y Júpiter, las más poderosas deidades de los panteones griego y romano respectivamente.

A la rapidez de las bestias y del rayo se agrega el temor que provocan estas cuestiones en el común de la gente, lo cual hace que tales animales, así como el relámpago, se conviertan en símbolos perfectos de poder. Y el provocar temor ha sido una muestra más del poder (político), lo cual es comprobable hito-históricamente desde antes de que nos lo dijera Thomas Hobbes -"La política y el poder han de fun-

\footnotetext{
${ }^{7}$ Adolfo Vásquez Rocca, "Sloterdijk y Canetti: El detonante iconográfico y operístico de la política de masas”. En Nómadas. Revista Crítica de Ciencias Sociales y Jurídicas,N 15 (2007).

${ }^{8}$ Karl Popper. La sociedad abierta y sus enemigos (México: Paidós, 2010), 23.

${ }^{9}$ Canetti. Masa y poder.
} 
TEMPUS. Revista en Historia General Medellín (Colombia), 2018, septiembre-octubre, número 8

darse en el miedo, la pasión racionalizante por excelencia, que fuerza a los hombres a calcular y a reconocer la verdad apodíctica de las «leyes naturales»". ${ }^{10}$

Siguiendo esta misma línea, Canetti luego nos comenta cómo algunos gobernantes son el tiempo, se convierten en el tiempo mismo. Cuestión que aconteció en particular en las épocas más arcaicas. Lo siguiente es un dechado inmejorable del tiempo como poder:

"Es conocido cómo la vida de ciertos individuos sirvió para realizar los primeros resúmenes temporales de grupos mayores de hombres. Los reyes, que lo eran por determinados lapsos de tiempo, encarnaban este tiempo para todos. Su muerte, debida a la disminución de su pleno vigor o acaecida más tarde, correspondiendo a la duración natural de su vida, señalaba siempre un período del tiempo. Ellos eran el tiempo, entre uno y otro el tiempo se detenía y se buscaba que tales períodos intermedios -interregnos- duraran lo menos possible". 11

Los individuos se convierten en el tiempo mismo cuando gobiernan, cuando tienen el poder. Aquí ya parece que el tiempo no es un arma del poder, sino que es el poder mismo. La vinculación entre los gobernantes y el tiempo se aprecia en Occidente desde tiempos inmemoriales, en la Grecia Antigua la monarquía estaba vinculada con ciclos de tiempo especialmente en el ámbito metafórico que representa la mitología, como nos comenta George Thompson: "Cada ocho años, Minos, rey de Cnossos, acostumbraba retirarse a la Caverna de Zeus para comulgar con su dios. Cada ocho años los atenienses solían enviar un tributo de sacrificio [... $]{ }^{12}$ Ser parte del poder, de la dominación, del gobierno, significa ser el tiempo. Poder y tiempo son consustanciales, son una misma cosa en los reyes que menciona Canneti.

\footnotetext{
${ }^{10}$ Luis Salazar C. "Las raíces político-intelectuales del totalitarismo" En La tenacidad de la política (México: Universidad Nacional Autónoma de México, 1995), 33.

${ }^{11}$ Canetti. Masa y poder, 397.

${ }^{12}$ George Thomson. Los primeros filósofos (México: Universidad Nacional Autónoma de México, 1988), 151.
} 
En la Era Industrial las máquinas "son" el tiempo, ellas controlan a los trabajadores y a todo tipo de individuos en general porque controlan (y manipulan) el tiempo. "El cronómetro y el ergógrafo registran y controlan los movimientos del hombre, como el termómetro registra las oscilaciones de temperatura en la caldera". ${ }^{13}$ Podemos decir que la teoría de Canetti bien se puede aplicar a los grandes burgueses o industriales, como a los políticos y científicos de la actualidad, quienes al controlar ellos a las máquinas o medios (de comunicación como televisión, internet, etc.) que "son" el tiempo ejercen el poder sobre los demás. Y, hablando de la "rapidez", debemos de recordar que con mucha frecuencia se considera que, entre más "rápida" es una máquina (de producción, de navegación en internet, de transporte, etc.), ésta es mejor y/o más poderosa.

Uno de los rasgos más característicos del poder es el crecimiento, en cualquier ámbito, incluyendo el crecer en (el) tiempo. Por esto es que entre mayor tiempo haya dominado una específica persona, dinastía o nación, mayor será su reputación de poderío. "En la grandeza con que sueñan los hombres, el sentimiento de crecimiento biológico individual se alía con el sentimiento de acrecentamiento brusco [...]", ${ }^{14}$ la grandeza conlleva pues cuestiones psicológicas que son parte de la constitución humana según el italiano. Bien reafirma también Laski tal pulso biológico por el poder, en su caso aquel que apreció en el siglo XVII:

"Para el hombre el proceso vital es una búsqueda continua de las satisfacciones que proporciona la sensación de poder. Podemos ver tal actitud en un santo como Spinoza, por un lado; por el otro, en un aristócrata mundano como La Rochefoucauld. Se concibe al hombre como lanzado a una lucha por la existencia en la que consigue triunfar por su poder para dominar el medio; y ese poder es, a su vez, un producto del apetito satisfecho. Esta pasión por el poder es tan obstinada en Hobbes, que solo la mano vigorosa del gobierno despótico puede dirigir sus acciones". ${ }^{15}$

\footnotetext{
${ }^{13}$ Hans Freyer. Teoría de la época actual (México: Fondo de Cultura Económica, 1966), 39.

${ }^{14}$ Canetti. Masa y poder, 406.

${ }^{15}$ H. J. Laski. El liberalismo europeo (México: Fondo de Cultura Económica, 1939), 110.
} 
TEMPUS. Revista en Historia General Medellín (Colombia), 2018, septiembre-octubre, número 8 ISSN: 2422-2976

Aquí podemos apreciar que para Canetti, como para Spinoza, para La Roche, Foucault, para Hobbes, como para otros grandes pensadores, el poder es una cuestión natural, algo común en cualquier ser humano. Tan común, que podemos imaginar que si el tiempo se pudiera poseer materialmente el humano se obstinaría por agarrarlo, guardarlo en la mejor caja fuerte que se posea y cuidarlo.

Entonces, si alguien desea ser más poderoso, debe durar más tiempo en la cumbre. Cuanto mayor sea el tiempo que un gobernante haya mandado, mayor habrá sido su poder. Una de las razones de la certeza de este argumento radica en que: entre mayor duración haya tenido el mandato de una persona, se incrementa con seguridad el número de individuos que pudo haber ordenado, subyugado, influido, repercutido, etc. Si un gobernante dura más en la cumbre, simplemente aumenta el número de individuos en los que tuvo ascendencia y su gobierno o liderazgo se mantendrá asimismo durante más tiempo en el recuerdo de un pueblo o pueblos. Si "la decisión de un sujeto se transfiere a la decisión de otro, de modo que éste, al tomar decisiones ulteriores, tiene en cuenta la decisión anterior como presupuesto de su acción", ${ }^{16}$ entonces las decisiones de aquel que haya detentado el poder durante más tiempo, por consecuencia obvia, serán tomadas como leyes durante más tiempo y por un mayor número de personas. Tal es uno de los motivos básicos de que los poderosos se quieran perpetuar en su poder y de su obsesión por sobrevivir indefinidamente.

Los poderosos por lo general se consideran a sí mismos invulnerables en mayor o menor medida, y siempre andan en busca de la supervivencia. Dice Canetti:

“[...] detrás de cada paranoia, como detrás de cada poder, se halla la misma tendencia profunda: el deseo de barrer a los otros del camino, para ser el único, o en la forma más atenuada y admitida a menudo, el deseo de servirse de los demás para que con su ayuda uno llegue a ser el único. ${ }^{17}$

\footnotetext{
${ }^{16}$ Rabotnikoff. En busca de un ..., 272.

${ }^{17}$ Canetti. Masa y poder, 459.
} 
En la identificación de poder con tiempo hayamos una misma búsqueda de ser los únicos. El poderoso sólo busca ser él el poderoso. Canneti sabía muy bien lo anterior y es una de las características que más atacó del poderoso desorbitante, a decir de Ishaghpour, ese ataque tiene su origen en la cualidad de poeta de Canetti:

"Su desconfianza hacia lo único y lo idéntico, que son los principios mismos del poder, que nos atrapan en sus fauces y nos imponen la terrible tiranía de la unicidad, mientras que el verdadero poeta es sacudido por la fiebre de la diferencia. Su rechazo hacia aquellos que tratan de dotarse a cualquier precio de una coherencia espiritual y envejecen rápidamente, que se convierten en servidores de su propio nombre, de la identidad que este presupone". ${ }^{18}$

El poeta desordena, el gobernante ordena (en todos los sentidos). Y en las ordenaciones del tiempo se busca que sólo haya una ordenación; es extraño e inadmisible para los gobernantes que su nación tenga más de un calendario, que tenga más de una forma de medir el tiempo, que posea más de una (hito-)historia oficial.

El intelectual fue muy certero al aseverar que el poderoso desea ser uno solo o estar concentrado en un solo grupo; las monarquías duales o las naciones con múltiples focos de poder son dechados de fracasos políticos hito-históricos. Por ello es que podemos extrapolar y asegurar que aquel que ejerce el poder establecerá su propia cronología y hará de ella, por todos los medios, la única. Así, una muestra actual de lo anterior es el de la máquina propagandística y política estadounidense, la cual deliberada, sagaz y simbólicamente marcó un antes y un después en la hito-historia del mundo con el suceso del 11 de septiembre de 2001. Estados Unidos impuso a esta fecha como el inicio de una nueva era, de una nueva época y cronología mundial; su estrategia triunfó en gran medida pues, más de quince años después de aquel punto en el tiempo, podemos decir que cualquier habitante del mundo medianamente informado sabe a qué hecho hito-histórico se alude con "11 de septiembre". Por ende, podemos afirmar que un grupo de personas -estadounidenses- interpretó al suceso ocurrido en Estados Uni-

\footnotetext{
${ }^{18}$ Ishagpour, "Metamorfosis e identidad en Elias Canetti", 33-34.
} 
TEMPUS. Revista en Historia General Medellín (Colombia), 2018, septiembre-octubre, número 8 ISSN: 2422-2976

dos en este punto de la historia como trascendente no sólo para su país sino para todo el mundo, convirtiéndolo de inmediato en un suceso hito-histórico mundial. Han intentado lo referido muchos otros regímenes a través de la historia; los revolucionarios franceses del XVIII al instaurar su calendario "republicano", los soviéticos al intentar tomar a 1917 como el inicio de una nueva nación, entre muchos otros.

Un dechado más sofisticado de la manipulación de la ordenación del tiempo como muestra de poder, en el campo ideológico-intelectual, los encontramos recurrentemente en Europa. El eurocentrismo de la clase intelectual europea (y del resto del mundo) hizo que continuamente se marcara la historia universal de acuerdo a los tiempos de la historia de Europa. La "Época Moderna", la "Época Contemporánea", la "Era Industrial", el "Renacimiento", etc., son ideas y cronologías creadas por aquel continente como demostración "científica" de su poderío y de su apogeo y que el resto del mundo aún sigue obedeciendo.

Borges nos proporciona un argumento que explica un por qué de la utilización del tiempo como arma de poder. Tal razonamiento psicológico y ontológico es el siguiente: "Es sabido que la identidad personal reside en la memoria y que la anulación de esa facultad comporta la idiotez. Cabe pensar lo mismo del universo. Sin una eternidad, sin un espejo delicado y secreto de lo que pasó por las almas, la historia universal es tiempo perdido [...]" ${ }^{19}$ Esta es una razón por la cual los poderosos hacen uso del tiempo para sus designios; si no eres parte del tiempo, de la hito-historia, es como si no existieras. La eliminación de una persona o un grupo de personas de la hitohistoria es una forma de opresión y de sujeción política (el faraón Akhenatón fue uno de los primeros gobernantes, que se conozca, en sufrir la eliminación de su nombre y actos de los registros estatales).

La amenaza de exclusión de la continuidad temporal es una vía para dominar a los otros. La prerrogativa de los Estados de privar de la libertad a los malhechores, criminales y opositores, no es sino también una manera de privar a las personas de se-

\footnotetext{
${ }^{19}$ Jorge Luis Borges. Historia de la eternidad (Madrid: Alianza Editorial, 2005), 38.
} 
guir perteneciendo a la continuidad temporal cotidiana. “[...] a partir de un momento preciso del tiempo, la historia ha dejado de ser real. Sin darnos cuenta, la totalidad del género humano ha abandonado de pronto la realidad. Todo lo que haya pasado desde entonces ya no es cierto, pero no podemos darnos cuenta". ${ }^{20}$ No sólo se trata de privar de la libertad física sino de ocultar a los alteradores del orden de la continuidad del tiempo.

El razonamiento de Borges también nos lleva considerar que si el universo no fuera imaginado como eterno entonces gran parte de la existencia carecería de sentido (cuando dice que el existir sería un tiempo perdido). De lo cual podemos extraer una razón más de la importancia del tiempo para el poder: si un Estado, dinastía, religión, etc., no se asumen como eternos (o al menos no declaran que planean perpetuarse durante un gran periodo), entonces decrece impresionantemente su poder porque decrece su crédito-credibilidad (al menos en términos propagandísticos e ideológicos), y no se les considerará con seriedad. Es muy visible la inviabilidad política y existencial para un gobierno o un régimen de (auto)afirmar que su poder tiene un tiempo limitado. Podemos citar el ejemplo histórico de la Antigua Roma que, conociendo la verdad de lo anterior, padecía sendos temores cuando se hablaba de su probable o incluso de su próximo fin; los mitos y profecías crepusculares del fin de los tiempos atormentaron siempre a los romanos por predecir la caída de Roma en un específico número de años. ${ }^{21}$

Es decir, si los gobernantes de una nación llegasen a afirmar que el Estado ensí (no su régimen, partido, dinastía, etc.) al que lideran sólo durará, digamos, unas cinco décadas, entonces dejan de tener sentido muchas o todas sus acciones -políticas, administrativas, sociales, etc.-, pues carecerían de cualquier continuidad más allá de cincuenta años. En la Antigua Roma, como en muchos otros regímenes, el hablar de un próximo fin para la propia nación tal como se le conoce es un rasgo distintivo de que en ese régimen se está viviendo una crisis. Lo mismo sucede en términos biológicos, cuando se comienza a hablar de la muerte o final de una persona, con excesiva

${ }^{20}$ Ishagpour, "Metamorfosis e identidad en Elias Canetti", 38.

${ }^{21}$ Véase Mircea Eliade. El mito del eterno retorno (México: Origen/Planeta, 1985). 
TEMPUS. Revista en Historia General Medellín (Colombia), 2018, septiembre-octubre, número 8

ISSN: 2422-2976

frecuencia, por lo común se debe a una crisis en la salud de esa persona (y en ciertos casos es consecuencia a una crisis existencial o psicológica) y si alguien puede modificar el final, es decir, el tiempo de una persona como ser viviente entonces tiene un poder sobre ella (se sabe del gran poder y prestigio que tienen los médicos, de cualquier tipo, en una sociedad). Si los gobernantes de la nación en que uno vive, a la que pertenece y en la que nació, no pueden asegurar la existencia de esa nación o ni habla de poder asegurarla durante un buen tiempo (que cubran varias generaciones al menos), los habitantes de esa específica nación o Estado perderían parte del sentido de sus propias existencias porque estarían perdiendo la posibilidad de perpetuar su identidad, su sociedad, sus leyes, estarían perdiendo la posibilidad de un futuro en la forma de su presente, para ellos mismos y para sus descendientes.

La idea de eternidad o continuidad duradera es indispensable para la psicología humana, Según Borges y Canetti, así como es útil para los poderosos en tanto que es otro medio para justificar y explicar su propio poderío. La existencia de cualquier ser sensible racional pierde fuerza si su final ontológico o terrenal está cercano, e incluso si sólo se declara que el fin está cerca, porque la intencionalidad de las acciones de todo ser racional perdería fuerza y sentido al no poder ser continuadas ni continuas. Por el contrario, el hombre adquiere "un poder infinito cuya fuente está en el infinito brotar del tiempo [...] que deja a cada nuevo día su frescor irresistible y su fuerza de surgimiento, aunque sea después de una medianoche trastornante y mortal", ${ }^{23}$ nos dice la filosofía de la historia bíblica; si le quitamos su supuesta eternidad al tiempo humano le quitamos una buena porción de su poder (psicológico).

\section{Generalizaciones equívocas sobre el uso del tiempo como arma del poder en de- terminadas sociedades.}

Antes de continuar, recordemos lo que afirmó José Gaos acerca de la temporalidad de la humanidad: "los cambios históricos del mundo humano parecen tener lugar

\footnotetext{
${ }^{23}$ André Neher, "La filosofía hebrea y judía en la Antigüedad". En El pensamiento prefilosófico y oriental (México: Siglo Veintiuno Editores, 1972), 64.
} 
a un ritmo mucho más rápido en la superficie política de la sociedad que en las profundidades morales de la vida privada, o en otros términos las formas de organización política cambiarían considerablemente más aprisa que las costumbres y las ideas morales". ${ }^{24}$ Considerando lo anterior como cierto podemos derivar varias consecuencias.

Podemos inferir, por ejemplo, que el uso del tiempo como herramienta de poder es más efectivo en el ámbito político que en el de las costumbres. O lo que es lo mismo, cuando el poderoso manipula el tiempo, las repercusiones son mayores en el ámbito público que en el privado. Un paradigma de lo anterior lo encontramos durante la Revolución Francesa; las consecuencias palpables ocurridas por la introducción del calendario republicano fueron meramente políticas, a lo más servían para que se observara que los revolucionarios vivían una temporalidad diferente a la que llevaban las monarquías europeas de la época. Tal calendario no tuvo repercusiones amplias en las costumbres, lo prueba el hecho de que una vez que se reinstauró el régimen monárquico se volvió sin más al antiguo calendario, y, cuando Francia volvió a ser República no por eso se regresó, a su vez, al calendario de los republicanos del 89. Como esta demostración podemos encontrar otras en la historia.

Continuando considerando el pensamiento citado de Gaos veamos otra ideageneralización de Canetti, éste nos comenta que "Podría decirse que la ordenación del tiempo es el más eminente atributo de toda dominación." ${ }^{25}$ Lo anterior es una afirmación quizá demasiado arriesgada y tajante; decir tal aserción es decir mucho, entendiendo que existen muchos, tal vez innumerables, atributos y formas de dominación. Estamos de acuerdo de que es muy probable que el uso y manipulación del tiempo es una de las formas más acabadas de ejercer el poder (de hecho se ha asegurado que el surgimiento del nacionalismo moderno se debió primordialmente al cambio de percepción del tiempo, de uno sagrado a uno mecánico), ${ }^{26}$ empero el asegurar que es tan solo

\footnotetext{
${ }^{24}$ José Gaos. Historia de nuestra idea del mundo (México: El Colegio de México/Fondo de Cultura Económica, 1973), 244.

${ }^{25}$ Canetti. Masa y poder, 395.

${ }^{26}$ Véase Gilberto Giménez, “Apuntes para una teoría de la identidad nacional”. En Sociológica, Revista del Departamento de Sociología, N 21 (1993).
} 
TEMPUS. Revista en Historia General Medellín (Colombia), 2018, septiembre-octubre, número 8 ISSN: 2422-2976

la ordenación del tiempo por sí misma la que da la mayor característica de poder y dominación es aseverar una exageración.

Antes de continuar hay que ser más específicos en qué es lo que entiende Canetti por "ordenación del tiempo": se refiere a la reordenación y control de la cronología cotidiana, entendiéndose por lo general las modificaciones al calendario y a la secuencia de los días, meses, años, etc., por parte del poder político que domina una determinada sociedad o que gobierna un específico pueblo o conjunto de pueblos. Especialmente se refiere a las modificaciones hechas por los poderes que son nuevos en las sociedades.

De lo dicho nos da como ejemplos los siguientes: I) la propaganda nazi de que el III Reich iba a durar mil años; II) la instauración del calendario juliano por parte de Julio César en la Roma antigua; III) el establecimiento de un mes con el nombre del soberano, tal como hicieron Julio César u Octavio Augusto; IV) el nombramiento de periodos de tiempo de acuerdo a las diferentes dinastías que gobernaron una sociedad, como tradicionalmente se hacía en China, etc.

Las generalizaciones y ejemplos hito-históricos que da Canetti se pueden rebatir. En el ejemplo I) es evidente para el que conoce la historia del III Reich que la manipulación y reordenación del tiempo que realizaron los dirigentes de este no es, por lejos, el "más eminente atributo" de todo su poder. Mucho menos cuando los nazis poseían armamento nunca antes visto en el planeta, un ejército sin parangón y un líder que no necesitaba de reordenar el tiempo para afianzar su poder. Es probable que su intención era hacer énfasis en el poderío de los nazis en general, sin precisiones ni acotaciones, el mismo Canneti sabía que el poder de aquellos no se veía con mayor claridad en la manipulación del tiempo: sabía que Adolf Hitler "Llegó a ser el mejor conocedor empírico de las masas y dominó todas las técnicas — crecimiento, repetición, lentitud, sentimiento de persecución, masa amotinada - que impiden la desagregación de la masa, para poder conseguir así la victoria". ${ }^{27}$ Es decir, tal líder alemán hizo uso de cuantas herramientas de poder tuvo a su disposición incluyendo la creación no sólo

\footnotetext{
${ }^{27}$ Ishagpour, "Metamorfosis e identidad en Elias Canetti".
} 
de un "nuevo" tiempo sino de una "nueva" política-religión en Alemania, una que hizo uso al por mayor del "lamento" 28 (de haber sido víctimas, los alemanes, de los tratados tras la Primera Guerra Mundial entre muchas otras cuestiones).

II) la instauración del calendario juliano no fue tampoco la mayor muestra del poderío de Julio César, en realidad tal calendario se trataba de una mejora pragmática a la vida cotidiana romana y no precisamente una estrategia propagandística (realmente fue un beneficio pragmático al pueblo y esto se tradujo en un beneficio político para el César y su dinastía); mayor demostración de poder fue el control del pueblo bajo y de mucha parte de los ejércitos por parte de Julio César, III) como tampoco lo fue que un mes llevara su nombre, no lo fueron porque puede afirmarse con evidencia que para su época y para su pueblo fueron más importantes las modificaciones que realizó en torno a la legislación, la forma de gobierno, el ejército y las costumbres, y tales significaron un mucho mayor muestra de su poder; IV) tampoco el hecho de que todo un periodo de tiempo tenga el nombre de una dinastía es el mayor símbolo de poder de esa dinastía, porque esos nombramientos son, como se dijo, cuestiones de mera costumbre: por ejemplo, el hecho de que una época llevara el nombre de una familia, como en la cronología de China, ya no impactaba más en la mentalidad de la población china de la Época Contemporánea (siglo XIX en adelante).

Así, con otro contraejemplo o contrapunto hito-histórico, como es la Revolución Francesa y la instauración de su nuevo calendario, tampoco aquí podemos afirmar que tal manipulación del tiempo haya sido "el más eminente atributo de toda dominación" por parte de los revolucionarios. Tan solo el hecho de derrumbar un régimen con siglos y siglos de antigüedad y el impedir su reinstauración durante décadas fue una mayor demostración de poderío. Otra demostración mayor de poder sería la que especificó Alexis de Toqueville:

“[...] la igualdad natural de los hombres, la abolición de todos los privilegios de casta, de clase y de profesión [...], la soberanía del pueblo [...]

\footnotetext{
${ }^{28}$ Wolfgang Palaver, "The Ambiguous Cachet of Victimhood: Elias Canetti's Religions of Laments and Abrahamic Monotheism," The New Visibility of Religion: Studies in Religion and Cultural (2008): 68-87.
} 
TEMPUS. Revista en Historia General

Medellín (Colombia), 2018, septiembre-octubre, número 8

ISSN: 2422-2976

Todas estas doctrinas no son sólo las causas de la Revolución [...], son lo más fundamental, lo más duradero y lo más cierto que hay en sus obras, al correr del tiempo". ${ }^{29}$

Subrayemos aquello de que fueron lo más duradero, y por ello, fueron unas de las mejores muestras del poder que ejercieron los revolucionarios. Además tales modificaciones a las cronologías y a los calendarios se quedaban, como afirmaba Gaos, en el orden de lo político. No aseveramos que la re-ordenación del tiempo no sea una preclara muestra de dominación en los casos mencionados por el intelectual búlgaro, sino que aseguramos y ejemplificamos que la susodicha ordenación no es la mayor muestra de poder como aseguró Canetti.

Los revolucionarios franceses entraron en la hito-historia no porque sólo hayan asesinado a Luis XVI o porque hayan cambiado el calendario francés, sino porque exigieron sus propios derechos y porque repudiaron los privilegios de otros: "Una clase solamente entra en la historia cuando se constituye en quejoso ante su tribunal". ${ }^{30}$ El estar o aparecer en la hito-historia, o en la temporalidad, es una forma básica de poder, incluso en los no poderosos: la capacidad de fuerza de los obreros no se aprecia hasta que realizaron sus primeros movimientos sindicales y sus primeras huelgas; la capacidad de organización de los afroamericanos en Estados Unidos no se aprecia hasta que lucharon por los derechos civiles; un caso más claro es el de los pueblos primitivos y sin escritura, lo cuales no entraron en la "historia universal" creada en el siglo XIX hasta que son insertados en la cronología de los europeos, nótese, en la cronología de los dominadores del mundo en el XIX.

En otro pasaje Canetti nos asegura que el poderoso debe de mantenerse alejado del resto de la población, es decir preservar "la más nítida de las distancias; en ello, no sólo por su brillo, él es el sol o, más ampliamente, como entre los chinos, el cielo". 31 Tal distancia del soberano propuesta por Canetti también es extensiva al

\footnotetext{
${ }^{29}$ Alexis de Tocqueville. El Antiguo Régimen y la Revolución (México: Fondo de Cultura Económica, 2006), 112.

${ }^{30}$ Canetti. Masa y poder, 203.

${ }^{31}$ Canetti. Masa y poder, 203.
} 
plano temporal, como el caso de la múltiple cantidad de poderosos que hacían y hacen esperar ingentes cantidades de tiempo para tener un encuentro con ellos. Dicho sea de paso, es probable que esto último se deba también a una simulación de la realización de muchos trabajos y actividades por parte del gobernante.

Quizá Canneti, al hablar de la distancia tanto física como en el orden temporal que debe guardar el gobernante, se refiera eminentemente a aquellas sociedades despóticas o absolutistas, como fueron la China de los Ming o la Francia de Luis XIV, porque no podemos aceptar la generalización del italiano de que todo poderoso debe mantener "la más nítida de las distancias" en cualquier época y lugar. Tal generalización es equívoca entonces en el sentido de que no es siempre aplicable. Por ejemplo, en las democracias occidentales contemporáneas los presidentes o primeros ministros deben permanecer en la mayor cercanía a su pueblo o a su electorado -al menos en tiempos de elecciones. Su postura de que mantener distancia es muestra de poder de hecho se opone, me parece, a su teoría de que el ejercer poder implica comandar directamente a los individuos cercanos, y entre más cercanos sean los individuos al gobernante más se puede ejercer el poder sobre ellos. Esa teoría, dice Canetti, tiene su origen en la naturaleza; el león ejerce poder y domina en su hábitat porque, al rugir, hace huir a los demás animales, es decir, les comanda alejarse.

"Derivo la noción de mandato [comandar] -biológicamente- de la orden de volar. Creo que la amenaza de un animal que se alimenta de otros animales lleva a éstos a tomar vuelo. Un león cazando que muestra su presencia a otros animales por medio de su rugido tiene el efecto de hacerlos volar [huir]. Y esto me parece ser el germen del mandato [comandar] como subsecuentemente se desarrolló y se convirtió en una importante institución de la sociedad humana". ${ }^{32}$

Pues, si el león no estuviera cerca de los demás animales entonces no podría ejercer su poder de ahuyentarlos, no podría atemorizarlos. De hecho, en las democracias actuales los líderes demócratas y/o presidentes (los leones “domesticados”) se

${ }^{32}$ Canetti, "Crowds and Power. Conversation with Elias Can-etti," en Can one live after..., 199 -200 . 
TEMPUS. Revista en Historia General Medellín (Colombia), 2018, septiembre-octubre, número 8

ISSN: 2422-2976

mantienen lo más accesibles posible ante los demás ciudadanos -aunque sea aparentemente-, si no hacen esto tienen el riesgo de perder su mismo poder. No sólo en este caso los gobernantes no mantienen su distancia ante los demás, también encontramos en la hito-historia otros casos: ciertas monarquías medievales europeas, como la inglesa o la francesa. En los reinos inglés y francés se poseía un claro afán por parte de la monarquía para mantenerse omnipresente física y temporalmente o, en otras palabras, se tenía en mente la idea de que cualquier institución de administración, guerra, religión o beneficencia, proviniera -y se supiera que provenía- del soberano. Era como aquello de los dos cuerpos del rey, uno que era el que biológicamente le pertenecía, y el otro que era suprasensible y que se apreciaba a través de las instituciones que él creaba, mantenía y financiaba.

Así, lo referido por Canetti de que el poderoso debía de mantener las puertas cerradas para acceder a él, o que debía construir palacios con cada vez más salones a su alrededor, no son sino afirmaciones que en la realidad poco se llevaron a cabo y que fueron casos aislados. Como contraejemplo a lo referido por nuestro intelectual, tenemos a los templos de los dioses poderosos (en las religiones tanto monoteístas como politeístas), los cuales siempre están abiertos a todos, como la mayoría de las iglesias católicas y de las pagodas. Entre más poderoso es un dios más visible debe de ser su templo, por ello es que el templo de Júpiter dominaba el corazón de la Roma antigua, pues tal dios era considerado el líder de los romanos. ${ }^{33} \mathrm{Al}$ igual, el dominio y la manipulación del tiempo por parte de los dioses debía de ser siempre visible; como lo apreciamos en el hecho de que las iglesias católicas vayan marcando las horas y les sea posible hacer saber este hecho a toda la comunidad mediante el omnipresente sonido de las campanas.

Borges afirmó que "es sabido que la identidad personal reside en la memoria y que la anulación de esa facultad comporta la idiotez" aludiendo a que el hombre sin noción de su historia personal o de su cronología es como si fuera un incapaz mental o como si ni siquiera existiera. Lo dicho por el argentino es afín al argumento que

\footnotetext{
${ }^{33}$ Véase Robert M. Ogilvie. Los romanos y sus dioses (Madrid: Alianza Editorial, 1995).
} 
nos proporciona Canneti al respecto del olvido: "Un hombre que ya no quiere saber qué edad tiene, ha terminado con su vida [...]. Periodos de desorientación temporal en la existencia de los individuos como en las de enteras culturas son períodos de vergüenza, que se procurará extirpar lo más de prisa posible." ${ }^{34}$ Ambos hablan de que tanto el olvido como el adolecer de una temporalidad clara son situaciones provocadas por el desorden y la estupidez, ya sea individual o proveniente desde los poderosos. Sin embargo, veremos que esta generalización no es en esencia certera.

Friedrich Nietzsche nos recuerda que el olvido es indispensable para el funcionamiento del ser humano, y no sólo para esto, sino que justifica que el hombre se aleje de la memoria de su historia personal o grupal. El filósofo alemán comenta que existe una envidia del ser humano hacia los animales porque éstos carecen de memoria (independientemente de que esto sea cierto Nietzsche utiliza la idea para asegurar que es saludable el olvido) y, por ende, no les agobia el gran peso del pasado. El ser humano tiene una envidia hacia los animales porque éstos viven ahistóricamente. ${ }^{35} \mathrm{El}$ anhelo por una existencia ahistórica, radica en que este tipo de vivir es completo y absoluto, es un vivir sincero impetuoso y renovador, por carecer de un ominoso lastre.

Luego, en la deliberación nietzscheana encontramos un elogio para el individuo que no posee un tiempo ordenado y que no sabe de un pasado hito-histórico de su propia comunidad o de otras. Elogio cuyo motivo se encuentra en que tal individuo está revestido de una mayor fortaleza y de un mayor vigor ante las dificultades.

“[...] por mucho que la ciencia y el sentimiento histórico de un hombre sea muy limitado, por mucho que su horizonte sea tan estrecho como el de los habitantes del valle de los Alpes, por mucho que manifieste en cada juicio una injusticia y en cada experiencia la creencia errónea de ser el primero en formularla, este hombre, pese a todas sus injusticias y errores, conservará una insuperable salud y vigor y alegrará cualquier mirada". 36

\footnotetext{
${ }^{34}$ Canetti. Masa y poder, 396-397.
}

${ }^{35}$ Friedrich Nietzsche. Sobre la utilidad y el perjuicio de la historia para la vida [II intempestiva] (Madrid: Biblioteca Nueva, 1999).

${ }^{36}$ Friedrich Nietzsche. Sobre la utilidad...,45. 
TEMPUS. Revista en Historia General Medellín (Colombia), 2018, septiembre-octubre, número 8

ISSN: 2422-2976

Podemos además deducir que el individuo sin hito-historia es invulnerable al tiempo como un arma de poder, porque no se puede obligar a aquel que adolece de una cronología a seguir alguna otra, ni se puede emplear la hito-historia para ideologizarlo y controlarlo, pues ella aún no es parte de su idiosincrasia. Quizá por esto los pueblos más primitivos o más salvajes son los más reacios a una dominación de parte de una nación más avanzada, porque no están acostumbrados a estar inmersos en alguna temporalidad, y especialmente reacios han sido los denominados "pueblos sin historia" porque si ellos no tuvieron un pasado, mucho menos tuvieron la intensión de pertenecer al pasado de algún otro pueblo. El individuo sin tiempo es más fuerte porque actúa, digamos, con mayor naturalidad y, por el contrario a lo sugerido por Borges y por Canneti, no posee rasgo de estupidez alguna, al menos que estupidez sea convertida en sinónimo de ignorancia, y sabemos que no son sinónimas.

Nietzsche continuó arremetiendo contra el exceso de noción de temporalidad, porque decía que "daña a lo viviente", nosotros agregaremos que tal exceso permite un mayor control de las personas. El hombre, aseveraba Nietzsche, debía de ser suprahistórico porque era preferible dar preeminencia al vivir que al tener una noción de un pasado, "estar seguros de poseer más vida" asegura al hombre un futuro, más que cualquier sabiduría -histórica. También porque ese conocimiento histórico puede convertirse en "una especie de conclusión para la vida", ${ }^{37}$ demeritando la propia existencia.

Y porque el tiempo y/o la hito-historia son empleados por un poder que precisamente no es histórico es que el alemán asegura que puede haber una degeneración existencial proveniente de la utilización del pasado. En otras palabras, está consciente de que el tiempo es una herramienta del poder, por ende, ataca despiadadamente a la obcecación por las cronologías y al estudio en exceso del pasado, puesto que estas cuestiones no son sino manipulaciones del poder. Un poder que puede impedir la grandeza en los individuos, ¿por qué?, porque les acorta la oportunidad de ser únicos. El tiempo bien puede emplearse para homologar a las personas, para mantenerlas ocupadas estudiando su propio pasado, para evitar que sean suprahistóricas y ahistóricas. Y

\footnotetext{
${ }^{37}$ Friedrich Nietzsche. Sobre la utilidad ..., 51.
} 
quien es tanto suprahistórico como ahistórico es el que no tiene consciencia del tiempo ni del pasado, no por estupidez o desorientación sino por, digamos, un exceso de sagacidad y fortaleza.

Para comprender mejor lo dicho hemos de recordar cómo describía Nietzsche a lo suprahistórico y a lo ahistórico. El primero es "el arte y la fuerza de poder olvidar y encerrarse en un horizonte determinado", y el primero consiste en "los poderes que desvían la mirada de lo que meramente deviene, dirigiéndola a lo que da a la existencia, el carácter de lo eterno e idéntico, hacia el arte y la religión". ${ }^{38}$ Aunque no concordamos en que el arte y la religión sean lo único que otorga lo eterno, sí afirmamos los aspectos benéficos del "poder" para hacer desviar la mirada, para hacer olvidar y constreñir a dejar de prestar atención al devenir. Por ello es que afirmo que unas cualidades esenciales del poder en general son lo ahistórico y lo suprahistórico, sin éstos el poder estaría incapacitado de emplear tanto a la hito-historia como al tiempo como sus herramientas (porque estaría absorto en el mero estudio del tiempo). La idea, pues, de que el olvido de la hito-historia (o la inexistencia de una para la nación) y el carecer de una ordenación del tiempo son provocados por la ineptitud o la ausencia de un poder fuerte, es una que sólo es verdadera en contadas ocasiones.

\section{Argumentaciones finales.}

El tópico de la utilización del tiempo como un arma por parte de los diferentes tipos de poder - político, social y religioso, principalmente- a través de las diversas épocas de la humanidad es uno sobremanera interesante y por demás esclarecedor del funcionamiento de los individuos, los pueblos y los Estados. El premio nobel de literatura, Elias Canneti, nos ofreció una multiplicidad de ejemplos de la utilización del tiempo como poder. Y cabe aquí hacer un recuento de los argumentos que apoyamos, como de los que criticamos, a manera de conclusión. Ello también con la finalidad de apreciar, finalmente, si podemos decir que nuestras tres hipótesis propuestas en la introducción fueron acertadas. Las cuales sirvieron para nuestras aproximaciones y análisis del tiempo y el poder.

${ }^{38}$ Friedrich Nietzsche. Sobre la utilidad ..., 135-136. 
TEMPUS. Revista en Historia General Medellín (Colombia), 2018, septiembre-octubre, número 8 ISSN: 2422-2976

Subrayo cuatro proposiciones de Canneti que hemos considerado como certeras (hito-históricamente): 1) La velocidad o rapidez, como un acortamiento deliberado de las acciones en el tiempo, es demostración y significación de poder. 2) Los soberanos pueden convertirse simbólicamente en el tiempo mismo como evidencia de su poder, en especial en las épocas más arcaicas. 3) El incremento del tiempo de mandato y dominio de cualquier individuo significa un incremento de su poder. 4) El detentador del poder siempre hará lo posible para que la temporalidad en sus dominios sea solo una, es decir, establecerá una sola cronología, un solo calendario, una sola (hito-) historia oficial.

La proposición 1) apoya a la hipótesis que establecí al principio de este texto, a saber, que (a) es evidente el uso del tiempo como instrumento del poder, porque el aparentar velocidad es emplear el tiempo para incrementar el poder, aunque sea simbólicamente, y respalda a la hipótesis (b), el uso del tiempo por parte de los poderosos fue y es diferente en las diferentes épocas, porque pese a que en las más diversas épocas, desde la Antigüedad hasta la época Contemporánea, fue empleada la velocidad, el acortamiento del tiempo, como un símbolo de poder, sin embargo no fueron utilizados ni los mismos símbolos ni las mismas formas de coerción con respecto al tiempo, tampoco se usaron en la misma medida ni con los mismos propósitos. También apoya a la hipótesis (c) la idea del tiempo fue sentida de diversas formas por los diversos pueblos del mundo, porque, como refiero, diversos pueblos utilizaron diversos símbolos de velocidad; y mientras unos podían adorar a esos símbolos otros podían sólo temerles.

La proposición 2) apoya a nuestra hipótesis (a) porque el hecho de que el poderoso se confunda intencionalmente con el tiempo mismo es una forma de utilizar al tiempo como poder. Apoya a $(b)$ porque la fusión entre el gobernante y el tiempo varía a lo largo de las épocas: parece que entre más antigua sea una época, con mayor facilidad el poderoso se podía con-fundir con el tiempo mismo y aplicar distintos niveles de control-coerción. Y es consecuente con (c) porque no en cualquier cultura el gobernante se puede con-vertir en el tiempo mismo, ni el que domina puede marcar siempre la pauta del tiempo de sus subordinados. 
La proposición 3) por igual apoya con evidencia a nuestras tres hipótesis. A (a), porque el asegurar y declarar un dominio longevo significa hacer uso del tiempo para incrementar el poder (aunque sea por reputación). Secunda a la hipótesis $(b)$, porque pese a que en cualquier época, sea un dirigente de la más remota Antigüedad o el más actual de los líderes mundiales, todos hayan ambicionado aumentar su tiempo en el poder; ello no significa que hayan utilizado al tiempo para coaccionar de la misma forma. Y secunda a $(c)$ porque, aunque en cualquier cultura el poderoso desea perpetuarse, tampoco en todas se planea esa perpetuación de la misma manera.

La proposición 4 secunda con evidencia la hipótesis $(a)$, porque el hecho de que el poderoso establezca o cree una sola cronología, temporalidad o (hito-)historia oficial, es una muestra clara del uso del tiempo por parte del poder. Secunda también a la hipótesis $(b)$ porque hay excepciones al plan común de cualquier poderoso, en cualquier cultura, de establecer una sola cronología e hito-historia como muestra de su poder, las excepciones más notables son los llamados "pueblos sin historia" (entre otras). Considerando a estos pueblos, la proposición 4 también secunda a $(c)$, porque las culturas sin historia han existido en todas las épocas.

En cuanto a las refutaciones que hicimos al intelectual italiano, podemos decir que fueron básicamente tres: 1) La ordenación del tiempo no es "el más eminente atributo de toda dominación". 2) El poderoso no siempre debe de mantener "la más nítida de las distancias", ni en el espacio ni en el tiempo, para con los dominados. 3) Los "periodos de desorientación temporal en la existencia de los individuos como en las de enteras culturas" no siempre son períodos de vergüenza, y tampoco son provocados ni por un deseo de ya no existir, ni por una ineptitud.

\section{Bibliografía.}

Borges, Jorge Luis. Historia de la eternidad. Madrid: Alianza Editorial, 2005.

Canetti, Elias, "Crowds and Power. Conversation with Elias Canetti", en Can one live after Auschwitz? A philosophical reader, Rolf Tiedemann, editor. California: Stanford University Press, 2003. 
TEMPUS. Revista en Historia General Medellín (Colombia), 2018, septiembre-octubre, número 8 ISSN: 2422-2976 . Masa y poder. Horst Vogel, traductor. Madrid: Machark Editores/ Alianza Editorial, 1981. . Crowds and Power. Carol Stewart, traductora. Nueva York: The Viking Press, 1962.

Dilthey, Wilhelm. Teoría de la concepción del mundo. Eugenio Ímaz, traductor. México, Fondo de Cultura Económica: 1978.

Eliade, Mircea. El mito del eterno retorno. Ricardo Anaya, traductor. México: Origen/ Planeta, 1985.

Ellsworth Laing, Alexander James, "Blinded by His Own "Imagination": The Flaw in Cannetti's Crowd Theory." Social and Political Review volumen XXII (Dublin: Trinity College Dublin, 2011): 13-24.

Freyer, Hans. Teoría de la época actual. Luis Villoro, traductor. México: Fondo de Cultura Económica, 1966.

Gaos, José. Historia de nuestra idea del mundo. México: El Colegio de México/Fondo de Cultura Económica, 1973.

Giménez, Gilberto, "Apuntes para una teoría de la identidad nacional," Sociológica, Revista del Departamento de Sociología, número 21 (México: Universidad Autónoma Metropolitana, 1993).

Ishaghpour, Youssef, "Metamorfosis e identidad en Elías Canetti," Daimon Revista de Filosofía. Inés Campillo Poza, traductora, número 38 (2006): 33-48.

Laski, H. J. El liberalismo europeo. Victoriano Miguélez, traductor. México: Fondo de Cultura Económica, 1939.

Neher, André, "La filosofía hebrea y judía en la Antigüedad," en El pensamiento prefilosófico y oriental: volumen 1 (México: Siglo Veintiuno Editores, 1972): 52-77.

Nietzche, Friedrich. Sobre la utilidad y el perjuicio de la historia para la vida [II intempestiva]. Germán Cano, traductor. Madrid: Biblioteca Nueva, 1999.

Ogilvie, Robert M. Los romanos y sus dioses. Álvaro Cabezas, traductor. Madrid: Alianza Editorial, 1995.

Palaver, Wolfgang, "The Ambiguous Cachet of Victimhood: Elias Canetti's Religions of Laments and Abrahamic Monotheism," en The New Visibility of Religion: 
Studies in Religion and Cultural. Hermeneutics: M. Hoelzl, G. Ward, editores. (Londres: Continuum, 2008), 68-87.

Popper, Karl. La sociedad abierta y sus enemigos. Eduardo Loedel, traductor. México:

Paidós, 2010.

Rabotnikoff, Nora. En busca de un lugar común. México: Universidad Nacional Autónoma de México/Instituto de Investigaciones Filosóficas, 2005.

Salazar C., Luis, "Las raíces político-intelectuales del totalitarismo", en La tenacidad de la política. Nora Rabotnikoff, Ambrosio Velasco, Corina Yturbe, coordinadores. México: Universidad Nacional Autónoma de México, 1995), 29-48.

Stuart Mill, John. Sobre la libertad. Pablo de Azcárate, traductor. Madrid: Alianza Editorial, 1984.

Subirats, Eduardo, "La muerte y la civilización," en Filosofia y tiempo final. Luis Martín-Estudillo, compilador. Atizapán/Tuxtla Gutiérrez: Afínita Editorial, 2014.

Thomson, George. Los primeros filósofos. Margo López de Cámara, José Luiz González, traductores. México: Universidad Nacional Autónoma de México, 1988.

Tocqueville, Alexis de. El Antiguo Régimen y la Revolución. Martí Soler, traductor. México: Fondo de Cultura Económica, 2006.

Vásquez Rocca, Adolfo, "Sloterdijk y Canetti: El detonante iconográfico y operístico de la política de masas," Nómadas. Revista Crítica de Ciencias Sociales y Jurídicas, número 15 (Madrid: Universidad Complutense de Madrid, 2007).

Watson, Ian, "Elias Canetti: The One and the Many," Chicago Review volumen 20/21, número 4 (1969), 184-200.

\section{NOTA:}

Para una interesante reflexión en torno al cambio de la percepción de la muerte individual en la posmodernidad véase Subirats, Eduardo, "La muerte y la civilización", en Filosofía y tiempo final, 2.- edición, Luis Martín-Estudillo, compilador, Atizapán/ Tuxtla Gutiérrez, Afínita Editorial, 2014, pp. 41-46. 